\title{
The Use of a Game-Based Decision Aid to Educate Pregnant Women about Prenatal Screening: A Randomized Controlled Study
}

\author{
Erin Rothwell, $\mathrm{PhD}^{1,2}$ Erin Johnson, $\mathrm{PhD}^{1,2}$ Bob Wong, $\mathrm{PhD}^{1}$ Nancy C. Rose, $\mathrm{MD}^{1,3}$ \\ Gwen Latendresse, $\mathrm{PhD}^{1,2}$ Roger Altizer, $\mathrm{PhD}^{1} \quad$ Jose Zagal, $\mathrm{PhD}^{1}$ Marcela Smid, $\mathrm{MD}^{1}$ \\ Abby Watson, $\mathrm{MD}^{1}$ Jeffrey R. Botkin, MD, MPH${ }^{1}$
}

${ }^{1}$ Division of Medical Ethics and Humanities, School of Medicine,
University of Utah, Salt Lake City, Utah
${ }^{2}$ College of Nursing, University of Utah, Salt Lake City, Utah
${ }^{3}$ Division of Maternal Fetal Medicine, Intermountain Healthcare,
Murray, Utah Am J Perinatol 2019;36:322-328.
Address for correspondence Erin Rothwell, PhD, Division of Medical Ethics and Humanities, School of Medicine, University of Utah, 10 South 2000 East, Salt Lake City, UT 84112 (e-mail: erin.rothwell@nurs.utah.edu).

\begin{abstract}
Keywords

- prenatal screening

- decision aid

- games

- randomized controlled study

- education

Purpose This project developed and evaluated the efficacy of a game decision aid among pregnant women about prenatal screening in a randomized controlled study. Study Design Participants were recruited from an obstetric clinic of an academic urban medical center and randomized $(n=73)$ to one of two study groups: the control group ( $n=39)$ that used a brochure or the intervention group $(n=34)$ that also used a game decision aid.

Result Participants who played the game had higher knowledge scores ( $m=21.41$, standard deviation $[S D]=1.74)$ than participants in the control group $(m=19.59$; $\mathrm{SD}=3.31$ ), $p=0.004$. The median time of game playing was 6:43 minutes (range: $2: 17-16: 44)$. The groups were similar in frequency of completing screening after the study, control $=6(15 \%)$ versus intervention $=11(32 \%), p=0.087$. However, the more interaction with the game resulted in more positive attitudes toward screening. Conclusion The addition of a game decision aid was effective in educating pregnant women about prenatal screening. As other genetic testing decisions continue to increase within clinical care, game-based decision tools may be a constructive method of informed decision-making.
\end{abstract}

The American College of Obstetricians and Gynecologists (ACOG) recommends that prenatal care providers offer all women prenatal screening in the first trimester of pregnancy, regardless of age or genetic risk status. ${ }^{1}$ This has moved the focus of prenatal screening from a subset of higher risk women to all pregnant women. However, significant barriers remain for effectively informing women about the risks and options for identifying and managing chromosomal anomalies and heritable conditions during pregnancy. It is widely recognized that current standards for patient educa-

received

August 13, 2017

accepted after revision

June 26, 2018

published online

August 14, 2018

tion in this domain are largely ineffective. ${ }^{2-4}$ This is due to several factors, including limited appointment time by clinicians, the routinization of prenatal screening, lack of effective education interventions, and the continued expansion of testing content and options. Decisions about prenatal screening are based on pregnant women' values and knowledge and therefore clinicians are often challenged with being informative but nondirective. As such, new and innovative methods of promoting informed decision-making about prenatal screening among patients are needed.

Copyright $\odot 2019$ by Thieme Medical Publishers, Inc., 333 Seventh Avenue, New York, NY 10001, USA. Tel: +1(212) 584-4662.
DOI https://doi.org/ 10.1055/s-0038-1667371. ISSN 0735-1631. 
One approach for informing pregnant women about their options and outcomes of prenatal screening is the use of decision aids., ${ }^{5,6}$ Decision aids have been used in several medical contexts in which the treatment choices are equivalent in their benefits (e.g., survival) but have differing risks. Decision aids inform patients of their options, help clarify patient values, support patients' decision process, and enable patients to engage more actively in shared decision-making with their providers. ${ }^{7}$ They are important in helping patients make decisions about available options that involve tradeoffs in terms of outcomes and knowledge during pregnancy.

Most decision aids still use brochures or didactic presentations and do not include interactivity throughout the educational experience. Clinicians need innovative methods to educate patients. As such, interactive games have a longstanding history as effective interventions for learning and motivating health behavior. ${ }^{8}$ This is because contrary to information on paper or through other applications delivered on mobile devices or computers, games are generally not a one-time dissemination of information. The interactive component can provide large amounts of didactic content through unlimited opportunities to rehearse and personalize feedback associated with a game. Furthermore, players can choose various simulated roles and choices to explore different decisions on their own time even when the choices explored are value-laden and morally significant as may be the case in the context of prenatal screening. ${ }^{9,10}$ Also, games can increase personalization and relevance of an experience by providing a range of outcomes for players to experience, thus making them ideal for real-life health care decisions. ${ }^{11-13}$ These features can significantly increase users' attention and retention of knowledge compared with a brochure or pamphlet.

However, the nondirective nature of prenatal screening education poses significant challenges for the game context. Games are often engaging through the provision of rewards to the gamer for success in working through barriers and problems toward an ultimate goal. In the health care domain, games can use such reward strategies to promote knowledge and adherence to professional recommendations. In the context of prenatal screening, the goal is not to either promote or inhibit prenatal screening per se, rather they can also be used to promote informed decision-making, present multiple options in a nondirective manner, clarify internal values, and promote communication with providers. This makes them ideal for supporting patients facing complex decisions for which the "correct" answer comes from a deeply personal decision-making process. Specifically, these issues are important when making choices about noninvasive prenatal screening. As such, the purpose of this research was to develop and evaluate the efficacy of a game decision aid on knowledge and satisfaction about noninvasive prenatal screening among pregnant women through a randomized controlled study.

\section{Materials and Methods}

The goal of this research was to develop and evaluate the efficacy of a game decision aid intervention among pregnant women about knowledge on prenatal screening and satisfaction with this type of decision aid. The project received Institutional Review Board approval from the University of Utah (00080529).

\section{Participants}

Pregnant women were recruited from an obstetric (OB) clinic of an academic urban medical center in the intermountain west. Eligibility criteria included being English speaking, and less than 15 weeks' gestation and attending first $O B$ visit for a low-risk pregnancy.

\section{Procedures}

Potentially eligible participants were approached immediately before their first prenatal $\mathrm{OB}$ visit in the clinic waiting room. If they were interested in participating, eligible participants were asked to arrive 30 minutes prior to their second OB visit. Consistent with current guidelines, ${ }^{1}$ the official policy at the recruitment site was to offer all women prenatal screening regardless of age, family history, or other risk factors. Participants in both groups were given the brochure-based decision aid during their first $\mathrm{OB}$ visit in the clinic as part of routine care along with any physician communication, as per the practice of the individual clinician.

Prior to randomization, all participants provided written informed consent. Participants were then assigned based on the computer-generated simple randomization sequence to the usual care or game intervention group. Upon completion of the study, participants received a gift card. In the usual care group, participants were given the same brochure as in the clinic to remind them of content. Participants were welcomed to review the brochure as long as they liked before completing the surveys. After reviewing the brochure, participants completed the surveys.

The game intervention group was given the same brochure and instructions as the control group, but they were also asked to play for however long they wanted the game called "The Meaning of Screening." Participants then completed surveys after playing the game.

\section{Development of the Experimental Game Intervention} The brochure-based decision aid used in the clinic is based on ACOG guidelines. Using the same content of the brochure, the game, "The Meaning of Screening," was created in collaboration with the Entertainment, Arts, and Engineering program at the University of Utah. Initial focus groups $(n=3)$ with 22 pregnant women, their partners, and $O B$ health or genetic counseling professionals provided the initial data for development. Then, iterative team meetings with game engineers, geneticists, obstetricians, nurse midwives, social scientists, and health communication experts were then conducted to develop and implement the game for this study. The game experience was driven by an exploration of risk estimates for positive and negative screening outcomes and diagnostic testing outcomes by the woman's maternal age. Participants were able to "click" through various age groups of the pregnant avatars and see outcomes and likelihood of positive and negative results, including false-positives and false-negatives 


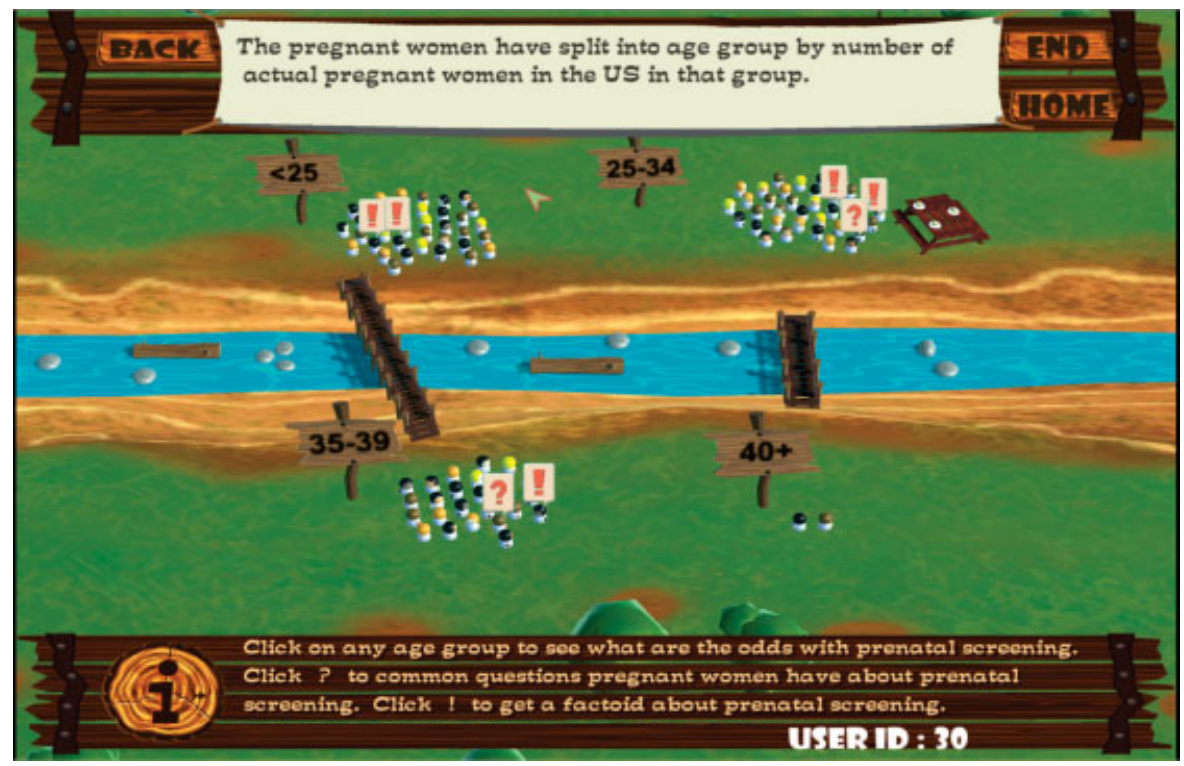

Fig. 1 Pregnant women by age.

from prenatal screening through diagnostic testing outcomes (-Figs. 1 and 2). As participants "clicked" through various outcomes, they were encouraged to have the avatars talk to each other about facts and reasons for pursuing or not pursuing prenatal screening. To address concerns regarding health literacy and numeracy, the number of avatars was represented to reflect the actual risk of these outcomes. For example, if there was a 1 in 100 chance of a false-positive, then 1 avatar was put under that outcome and 100 avatars were placed on the other side of the screen. The design layout of the game was pleasant, with bright colors and an agreeable outdoor environment that included trees, grass, and a river.

\section{Surveys}

Participants in both groups completed a knowledge survey about prenatal screening and diagnostic testing. Knowledge was measured with a 23-item survey (Prenatal Screening Knowledge Survey) developed by an expert panel of genetic counselors, physicians, social scientists, and data collection experts. Internal consistency was excellent in our sample $(N=73)$ with a Cronbach's $\alpha=0.78$ (see - Supplementary Material [available in the online version] for a list of questions).
The International Patient Aid Decision Aids Standards (IPDAS) Collaboration published a checklist of the criteria that should be included in a well-designed decision aids. ${ }^{14}$ Values clarification exercises were included as a critical component in the checklist. Values clarification exercises are processes to aid patients in clarifying their values and goals and improving alignment of patients' preferences with the treatments they actually receive. The survey included eight questions about values modified from Kuppermann et al. $^{3}$ Screening uptake and genetic counseling were abstracted from the chart review to examine whether participants pursued prenatal screening after completing the study and to control for participants who may have pursued prenatal screening or seen a genetic counselor prior to completion of this study (after the first prenatal visit and before the second prenatal visit). Surveys also included questions about the game in regard to neutrality of information, satisfaction with the prenatal screening education process, and satisfaction with the gaming experience. Finally, data analytics on game usage were also collected.

General linear modeling with SPSS Version 24 (corrected for inequality of variance where warranted) and chi-square

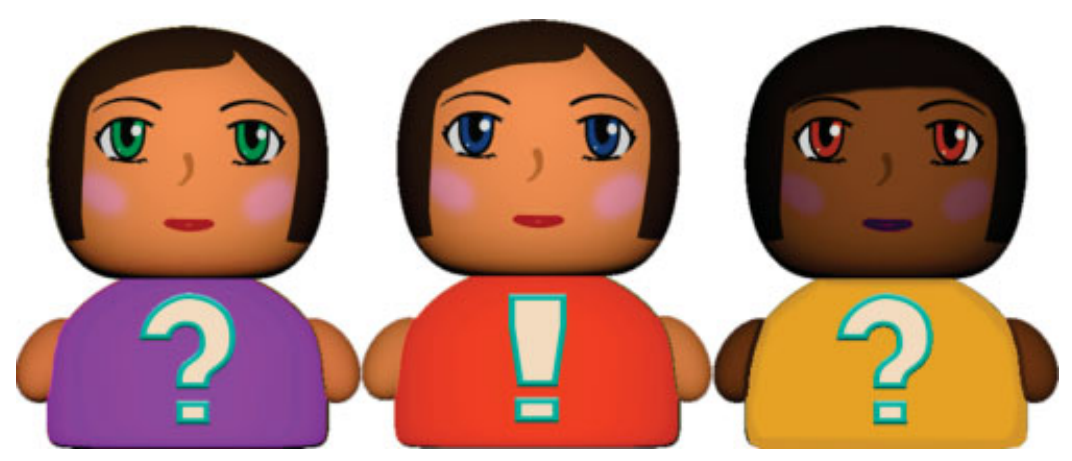

Fig. 2 Avatars. 
testing was used to assess group differences in knowledge, values, and screening/genetic counseling behavior. Spearman's rank correlation coefficient was used to assess the relationship between game usage (time and click data) and the outcome variables. The study was powered a priori (0.80), $\alpha=0.05$, to detect a medium/large effect size (Cohen's $d=0.67$ ) for the primary outcome of knowledge, assuming an $80 \%$ correct knowledge response, a standard deviation of $3 \%$ with equal groups of 36 participants.

\section{Results}

Seventy-nine participants were randomized to the two groups: 39 in the control group and 40 in the intervention group. There was a technical fault with the data analytics function for the Meaning of Screening game for the first three participants in the intervention group, and these participants were dropped from the analysis. Three participants exited the game within 20 seconds of beginning the game and were dropped from the analysis making our total sample ( $N=73$; 39 in the control group and 34 in the intervention group) (see CONSORT [CONsolidated Standards Of Reporting Trials] diagram in - Fig. $\mathbf{3}$ ).

The groups were equivalent on demographic variables (-Table 1). The average age of our participants was 29.82 (4.96) years old, $80 \%$ were White and $84 \%$ were Non-Hispanic,
Table 1 Demographics

\begin{tabular}{|c|c|c|c|}
\hline \multirow[t]{2}{*}{ Characteristics } & $\begin{array}{l}\text { Standard } \\
\text { of care }\end{array}$ & $\begin{array}{l}\text { Meaning } \\
\text { of screening }\end{array}$ & Total \\
\hline & $n=39$ & $n=34$ & $n=73$ \\
\hline $\begin{array}{l}\text { Age at enrollment } \\
\text { (years) }\end{array}$ & $\begin{array}{l}29.56 \\
(5.20)\end{array}$ & $\begin{array}{l}30.13 \\
(4.72)\end{array}$ & $\begin{array}{l}29.82 \\
(4.96)\end{array}$ \\
\hline \multicolumn{4}{|l|}{ Race } \\
\hline White & $33(84.6 \%)$ & $25(73.5 \%)$ & $58(79.5 \%)$ \\
\hline Non-White & $6(15.4 \%)$ & $9(26.5 \%)$ & $15(20.5 \%)$ \\
\hline \multicolumn{4}{|l|}{ Ethnicity } \\
\hline Hispanic & $4(10.3 \%)$ & 7 (22.6\%) & $11(15.7 \%)$ \\
\hline Non-Hispanic & $35(89.7 \%)$ & $24(77.4 \%)$ & $59(84.3 \%)$ \\
\hline \multicolumn{4}{|l|}{ Income } \\
\hline Under US\$24,999 & $4(10.5 \%)$ & $1(3.1 \%)$ & $5(7.1 \%)$ \\
\hline US $\$ 25,000$-US $\$ 50,000$ & $7(18.4 \%)$ & $5(15.6 \%)$ & $12(17.1 \%)$ \\
\hline US $\$ 50,001-U S \$ 100,000$ & $14(36.8 \%)$ & $16(50 \%)$ & $30(42.9 \%)$ \\
\hline US\$100,001-US\$150,000 & $8(21.1 \%)$ & $5(15.6 \%)$ & $13(18.6 \%)$ \\
\hline Over US\$150,000 & $2(5.3 \%)$ & $2(6.3 \%)$ & $4(5.7 \%)$ \\
\hline Not sure/did not answer & $3(7.9 \%)$ & $3(9.4 \%)$ & $6(8.6 \%)$ \\
\hline \multicolumn{4}{|l|}{ Education } \\
\hline $\begin{array}{l}\text { Less than college } \\
\text { graduate }\end{array}$ & $12(30.8 \%)$ & $12(37.5 \%)$ & $24(33.8 \%)$ \\
\hline $\begin{array}{l}\text { College graduate } \\
\text { and above }\end{array}$ & $27(69.2 \%)$ & $20(62.5 \%)$ & $47(66.2 \%)$ \\
\hline
\end{tabular}

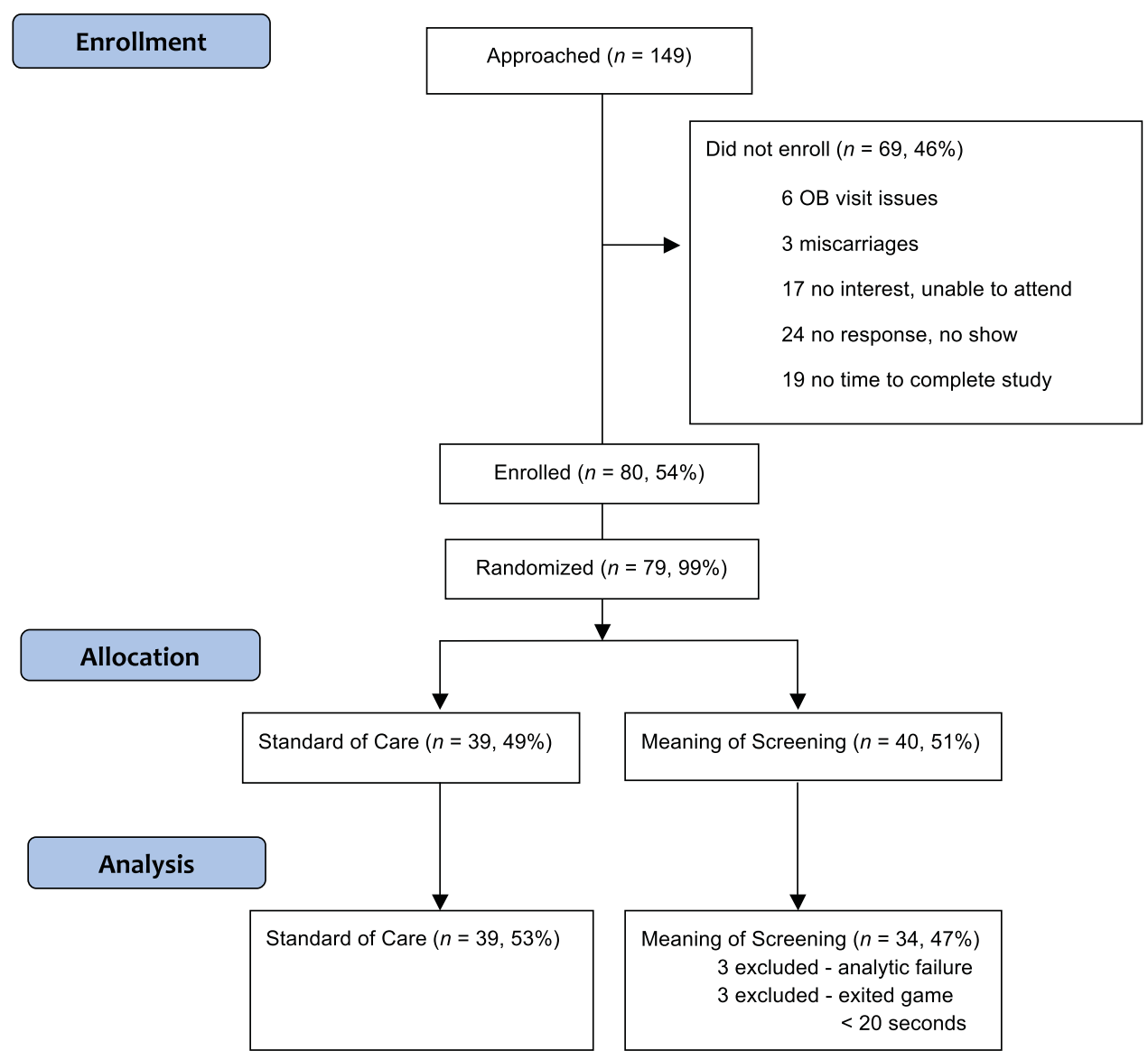

Fig. 3 CONSORT flow diagram. OB, obstetric. 
Table 2 Knowledge, values, and screening behavior

\begin{tabular}{|c|c|c|c|}
\hline Outcome & $\begin{array}{l}\text { Standard of care, } \\
n=39\end{array}$ & $\begin{array}{l}\text { Meaning of screening, } \\
n=34\end{array}$ & $p$-Value \\
\hline \multicolumn{4}{|l|}{ Knowledge } \\
\hline Knowledge total score ${ }^{a}$ & $19.59(3.31)$ & $21.41(1.74)$ & 0.004 \\
\hline \multicolumn{4}{|l|}{ Values } \\
\hline $\begin{array}{l}\text { Which would be harder for you: having a } \\
\text { child with Down's syndrome or having } \\
\text { a miscarriage that may be caused by a prenatal test? }\end{array}$ & $3.85(1.23)$ & $3.24(1.33)$ & 0.045 \\
\hline $\begin{array}{l}\text { If you were told that your fetus had } \\
\text { Down's syndrome, would you choose } \\
\text { to have an abortion? }\end{array}$ & $1.44(0.94)$ & $1.97(1.22)$ & 0.051 \\
\hline \multicolumn{4}{|l|}{ Screening behavior } \\
\hline Received screening after study & $6(15 \%)$ & $11(32 \%)$ & 0.087 \\
\hline
\end{tabular}

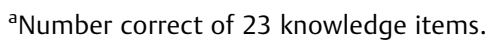

bSingle-item 1 to 5 scale (1, definitely worse to have a child with Down's syndrome; 5 , definitely worse to have a miscarriage).

'Single-item 1 to 5 scale (1, no, I definitely would not have an abortion; 5, yes, I definitely would have an abortion).

$66 \%$ had graduated college or more formal education, and $43 \%$ had an income between $\$ 50,001$ and $\$ 150,000$.

As hypothesized, participants randomized to the intervention group had significantly higher knowledge scores $(m=21.41$; standard deviation $[S D]=1.74)$ than participants in the control group ( $m=19.59$; SD $=3.31), p=0.004$ (see - Table $\mathbf{2}$ for the results).

Value clarification questions were also asked to control for beliefs regarding Down's syndrome and risks associated with diagnostic testing. For example, if participants self-reported values that indicated that they were more likely to risk a miscarriage from invasive screening tests than have a child with Down's syndrome, then these individuals were coded as "more likely to engage in prenatal screening." Participants in the two groups only significantly differed on two value questions. When asked, "Which would be harder for you, having a child with Down's syndrome or having a miscarriage that may be caused by a prenatal test?" participants playing the game reported higher scores toward harder having a child with Down's syndrome $(m=3.85 ; \mathrm{SD}=1.23)$ than those participants in the control group ( $m=3.24$; SD $=1.28), p=0.045$. The other question was "If you were told that your fetus had Down's syndrome, would you choose to have an abortion?" and participants playing the game reported higher scores toward termination $(m=1.97 ; \mathrm{SD}=1.22)$ than those in the control group $(m=1.44 ; \mathrm{SD}=0.94), p=0.051$. These variables were added as covariates to the analysis and did not significantly influence prenatal screening uptake between the two groups. All the other value questions were statistically equivalent between the groups.

To assess the efficacy of the game and to evaluate whether it influenced participants to take a particular screening decision, screening uptake and genetic counseling were obtained from the chart review. The groups were similar in frequency of having screening after the study (control $=6$ $[15 \%]$ vs. intervention $=11[32 \%] ; p=0.087)$.
The median time of game playing was 6:43 (range: 2:1716:44) and the median number of clicks on items within the game was 49 (range: 14-242). Time spent playing the game was not correlated with any of the outcomes. The number of clicks was correlated with the behavior of having screening performed after the study $\left(r_{s}=0.36 ; p=0.037\right)$. For participants in the control group, official time for reviewing the brochure was approximately 1 to 2 minutes as reported by research coordinators. Satisfaction results with the game decision aid are presented in -Table 3.

\section{Discussion}

Gaming is a pervasive aspect of American culture. About $60 \%$ of all Americans play computer or video games during their leisure time, and in most of those cases, they play for at least 3 hours per week. ${ }^{15}$ The average age of a player in the United States is 35 years old, and $41 \%$ of game players are women. In fact, women aged 18 or older represent a significantly greater portion of the game-playing population than boys aged 18 or younger. ${ }^{15}$ The widespread appeal of games among adults creates a unique opportunity for education within health care, allowing patients to actively engage with information, or play with it, as opposed to absorbing it in a didactic fashion.

This study developed and evaluated the efficacy of a game-based decision aid for prenatal screening among a general population of pregnant women compared with usual care (brochure-based decision aid). The results demonstrated high satisfaction and more time interacting with the information about prenatal screening in a game format that resulted in significantly higher knowledge outcomes. Furthermore, there were no differences between the two groups in prenatal screening uptake after the study. In general, the use of a game decision aid in this study suggests a new approach to promoting informed decision-making among pregnant women. 
Table 3 Satisfaction with the game decision tool

\begin{tabular}{|c|c|}
\hline $\begin{array}{l}\text { Questions about the } \\
\text { game experience } \\
(n=34)\end{array}$ & Percentage \\
\hline $\begin{array}{l}\text { How would you rate } \\
\text { the amount of information } \\
\text { you just received } \\
\text { about prenatal testing? }\end{array}$ & $\begin{array}{l}\text { 2.9\%: a little more than I needed } \\
\text { 97\%: about right or more than I needed } \\
\text { 2.9\%: a lot less than I needed }\end{array}$ \\
\hline $\begin{array}{l}\text { How clearly was that } \\
\text { information presented? }\end{array}$ & $\begin{array}{l}50 \% \text { : everything was clear } \\
47.1 \% \text { : most things were clear } \\
2.9 \% \text { : many things were unclear }\end{array}$ \\
\hline $\begin{array}{l}\text { How balanced (both the } \\
\text { pros and cons) was the } \\
\text { information } \\
\text { in the game? }\end{array}$ & $\begin{array}{l}\text { 17.6\%: clearly slanted toward screening } \\
\text { 32.4\%: slightly slanted toward screening } \\
50 \% \text { : completely balanced }\end{array}$ \\
\hline $\begin{array}{l}\text { Were there any tests or } \\
\text { procedures that you were } \\
\text { hoping to learn about } \\
\text { but were unable to find } \\
\text { in the program? }\end{array}$ & $\begin{array}{l}\text { 94.1\%: reported “no" } \\
\text { 5.9\%: reported "yes" }\end{array}$ \\
\hline $\begin{array}{l}\text { Were there any testing } \\
\text { strategies that you were } \\
\text { interested in that } \\
\text { were not discussed by } \\
\text { the game? }\end{array}$ & $\begin{array}{l}\text { 97.1\%: reported "no" } \\
2.9 \% \text { : reported "yes" }\end{array}$ \\
\hline $\begin{array}{l}\text { I would recommend } \\
\text { this game to a friend } \\
\text { who is pregnant. }\end{array}$ & $\begin{array}{l}88.3 \% \text { : agree or strongly agree } \\
11.7 \% \text { : probably not or no }\end{array}$ \\
\hline $\begin{array}{l}\text { I have a positive opinion } \\
\text { toward video games. }\end{array}$ & $\begin{array}{l}\text { 42\%: agree or strongly agree } \\
38.7 \% \text { : neither agree nor disagree } \\
19.4 \% \text { : disagree }\end{array}$ \\
\hline $\begin{array}{l}\text { Playing this game was a } \\
\text { new kind of experience } \\
\text { for me. }\end{array}$ & $\begin{array}{l}\text { 67.7\%: agree } \\
19.4 \% \text { : neither agree nor disagree } \\
12.9 \% \text { : disagree or strongly disagree }\end{array}$ \\
\hline $\begin{array}{l}\text { I found the experience } \\
\text { worthwhile. }\end{array}$ & $\begin{array}{l}\text { 73.5\%: agree or strongly agree } \\
12.9 \% \text { : neither agree nor disagree } \\
6.4 \% \text { : disagree or strongly disagree }\end{array}$ \\
\hline
\end{tabular}

Despite improved knowledge outcomes and high satisfaction with this type of decision aid, more in-depth research is needed to assess how the features of games specifically address the components of a decision aid, such as values clarification, decisional conflict, and shared decision-making with providers. Both values clarification and shared decision-making with providers are extremely important in this domain of prenatal care partly due to the voluntary nature of this type of screening test. Research has shown that information about prenatal screening is often offered to patients based on the perceptions by their prenatal care providers, including perceptions about risk and about whether a couple is likely to want or use the screening results. ${ }^{16,17}$ Regardless of the prenatal screening decision made by the couple or pregnant woman, clearly the decisions are heavily influenced by how, if at all, the provider communicates the screening options and information. ${ }^{17,18}$ More research is needed to assess how a game that allows exploration of different choices impacts shared decision-making with providers.

In addition, different choices and the potential outcomes of these choices as they relate to personal values and pregnancy outcomes could also be explored, which, in turn, may assist in more informed decision-making. Values are principles or standards of behavior an individual deems highly important in life. As discussed previously, values clarification is a critical component in decision aids, and games may be an ideal modality to explore different outcomes of prenatal screening from varying types of results. Thus, pregnancy outcomes of a diagnosis of a fetus with Down's syndrome or termination could be explored in a game setting that is private and allows more personal reflection prior to decision-making about prenatal screening. Future addition to the decision aid game could add these potential outcomes.

In addition, there were some interesting results relating to the appropriate use of a game format for a decision aid on health care decisions. Those who "clicked" more on the avatars to learn facts, and ask and answer questions between the avatars also had a higher uptake of prenatal screening. This could have been a spurious finding because time playing the game was not associated with prenatal screening uptake. However, it is interesting that increased interactivity with the game, self-driven by the woman, is associated with higher screening uptake but not with differences in knowledge. One possibility is that the process of seeing avatars, which reflect a diverse group of pregnant women discuss facts and questions about prenatal screening, may result in a more positive perspective toward screening. Alternatively, women who were predisposed to pursue testing may have spent more time with the game to better understand prenatal screening. Furthermore, the visual layout of the game was also positive in bright colors and a pleasant outdoor environment. However, this also made the game more attractive and resulted in more time spent with the game than the brochure.

Thus, the features that make games interesting may also promote a more positive attitude toward prenatal screening as opposed to not screening. It is important to maintain a nondirective nature in education for prenatal screening, and that may pose significant challenges for the game context. Games often are engaging through the provision of rewards to the gamer for success in working through barriers and problems toward an ultimate goal. In the health care domain, games can use such reward strategies to promote knowledge and adherence to professional recommendations. In our context, our goal is to neither promote nor inhibit prenatal screening per se but to promote informed decision-making, values clarification, and communication between partners driven by theory through serious game design. More research is needed to identify how these game features such as color scheme, game environment, and interactions and physical representation of avatars influence decision-making.

This study used a randomized design with a focus on screening choices including some information about diagnostic outcomes. However, it only included outcome data on cell-free DNA (cfDNA) and did not include outcome data that compared and contrasted cfDNA with other prenatal screening options. The research team purposefully limited the game to cfDNA at this stage of the research because implications for counseling and informed decision-making of pregnant women are similar for other prenatal screening tests. Despite cfDNA having better detection rate among older women, ${ }^{19}$ the general approach to education about prenatal screening across the different options is the same. 
Most $O B$ clinics provide brochures at the first prenatal visit, $^{20}$ and some may or may not discuss the options with their obstetrician and/or a genetic counselor. cfDNA was chosen because it has a better overall detection rate, and the purpose of the game was not to educate about each type of prenatal screening option and how each type of screening is conducted but if prenatal screening was an appropriate choice in general.

In addition, this study was only able to include a small sample of women with limited diversity from an OB clinic of an academic urban medical center. Next steps for the game design will need to include value preferences of the patient into the game as opposed to computerized survey questions to increase personalization prior to decision-making. Knowledge was only assessed after the intervention so that we are unable to explore knowledge gains over time. Finally, it is important that any future research assesses the neutrality of a gaming decision aid on outcomes. Any decision support tool should not encourage or discourage a particular choice and additional research on how entertainment or pleasant visual features may impact decisions without bias as well as how it impacts shared decision-making with providers is needed. Future research will explore the impact of this game with a more diverse sample, both nationally and in terms of racial/ethnic makeup.

\section{Conclusion}

Outcomes of this research show promise for the use of games to educate about prenatal screening as well as other genetic testing decisions. The game environment appeared to motivate participants to interact more with the information, resulting in higher knowledge. More research is needed to understand how the features of a game influence motivation to continue to play and impact patient decision-making and decisional outcomes.

\section{Funding}

This research was supported by the National Human Genome Research Institute (HD083832) and in part by the National Center for Advancing Translational Sciences of the National Institutes of Health under Award Number UL1TR001067. The content is solely the responsibility of the authors and does not necessarily represent the official views of the National Institutes of Health.

\section{Conflict of Interest}

None.

\section{Acknowledgment}

The authors would like to thank the Department of Obstetrics and Gynecology at the University of Utah for their assistance.

\section{References}

1 Committee on Practice Bulletins-Obstetrics, Committee on Genetics, and the Society for Maternal-Fetal Medicine. Practice Bulletin No. 163: Screening for Fetal Aneuploidy. Obstet Gynecol 2016;127(05):e123-e137

2 Gammon BL, Kraft SA, Michie M, Allyse M. "I think we've got too many tests!": prenatal providers' reflections on ethical and clinical challenges in the practice integration of cell-free DNA screening. Ethics Med Public Health 2016;2(03):334-342

3 Kuppermann M, Pena S, Bishop JT, et al. Effect of enhanced information, values clarification, and removal of financial barriers on use of prenatal genetic testing: a randomized clinical trial. JAMA 2014;312(12):1210-1217

4 Dyer J, Latendresse G, Cole E, Coleman J, Rothwell E. Content of first prenatal visits. Matern Child Health J 2018;22(05):679-684

5 Kuppermann M, Norton ME, Gates E, et al. Computerized prenatal genetic testing decision-assisting tool: a randomized controlled trial. Obstet Gynecol 2009;113(01):53-63

6 Leung CM, Ho GKH, Foong M, Ho CF, Lee PKK, Mak LSP. Smallgroup hypertension health education programme: a process and outcome evaluation. J Adv Nurs 2005;52(06):631-639

7 Stacey D, Bennett CL, Barry MJ, et al. Decision aids for people facing health treatment or screening decisions. Cochrane Database Syst Rev 2011;(10):CD001431

8 Brown SJ, Lieberman DA, Germeny BA, Fan YC, Wilson DM, Pasta DJ. Educational video game for juvenile diabetes: results of a controlled trial. Med Inform (Lond) 1997;22(01):77-89

9 Zagal JP. Ethical reasoning and reflection as supported by singleplayer videogames. In: Gibson D, Schrier K, eds. Designing Games for Ethics: Models, Techniques, and Frameworks: Information Science Reference. Hershey, PA: IGI Global; 2011:19-35

10 Sicart M. The Ethics of Computer Games. Boston, MA: MIT; 2009

11 Cannon-Bowers JA, Bowers C, Procci K. Using video games as educational tools in healthcare. In: Tobias S, Fletcher JD, eds. Computer Games and Instruction. Charlotte, NC: Information Age; 2011:42-72

12 Arnab S. Serious Games for Healthcare: Applications and Implications. Hershey, PA: IGI Global; 2012

13 Susi T, Johannesson M, Backlund P Serious Games: An Overview. Developing Industrial Strategies through Innovative Cluster and Technologies. Technical Report HS- IKI -TR-07-001. 2007

14 Volk RJ, Llewellyn-Thomas H, Stacey D, Elwyn G. Ten years of the International Patient Decision Aid Standards Collaboration: evolution of the core dimensions for assessing the quality of patient decision aids. BMC Med Inform Decis Mak 2013;13(2, Suppl 2):S1

15 Entertainment Software Association. Essential Facts about the Computer and Video Game Industry 2016 Sales, Demographic, and Usage Data. ESA Annual Report. Available at: http://www.theesa.com/wpcontent/uploads/2017/04/EF2017_FinalDigital.pdf

16 Hunter AG, Cappelli M, Humphreys L, et al. A randomized trial comparing alternative approaches to prenatal diagnosis counseling in advanced maternal age patients. Clin Genet 2005;67(04):303-313

17 Seavilleklein V. Challenging the rhetoric of choice in prenatal screening. Bioethics 2009;23(01):68-77

18 Paul D. The Politics of Heredity: Essays on Eugenics, Biomedicine, and the Nature-Nurture Debate. Albany, NY: State University of New York Press; 1998

19 Song K, Musci TJ, Caughey AB. Clinical utility and cost of noninvasive prenatal testing with cfDNA analysis in high-risk women based on a US population. J Matern Fetal Neonatal Med 2013;26 (12):1180-1185

20 Dyer J, Latendresse G, Cole E, Coleman J, Rothwell E. Content of first prenatal visits. Matern Child Health J 2018;22(05):679-684 